\title{
A Human Long Non-Coding RNA ALT1 Controls the Cell Cycle of Vascular Endothelial Cells Via ACE2 and Cyclin D1 Pathway
}

\author{
Wen Lia Rui Wang ${ }^{a}$ Jie-yi Ma ${ }^{\mathrm{b}}$ Mian Wang ${ }^{\mathrm{a}}$ Jin Cui ${ }^{\mathrm{a}}$ Wei-bin Wu \\ Rui-ming Liu ${ }^{b}$ Chun-xiang Zhang ${ }^{c}$ Wen Lib Shen-ming Wang ${ }^{a}$ \\ aDivision of Vascular Surgery, Guangdong Key Engineering Laboratory for Diagnosis and Treatment \\ of Vascular Disease, The First Affiliated Hospital, Sun Yat-sen University, Guangzhou, 'baboratory of \\ General Surgery, Guangdong Key Engineering Laboratory for Diagnosis and Treatment of Vascular \\ Disease, First Affiliated Hospital, Sun Yat-sen University, Guangzhou, China; 'Department of Biomedical \\ Engineering, University of Alabama at Birmingham, USA
}

\section{Key Words}

Long non-coding RNA • Endothelial cells • Angiotensin converting enzyme II • Cyclin D1 • Ubiquitination

\begin{abstract}
Background/Aims: ALT1 is a novel long non-coding RNA derived from the alternatively spliced transcript of the deleted in lymphocytic leukemia 2 (DLEU2). To date, ALT1 biological roles in human vascular endothelial cells have not been reported. Methods: ALT1 was knocked down by siRNAs. Cell proliferation was analyzed by cck-8. The existence and sequence of human ALT1 were identified by $3^{\prime}$ rapid amplification of cDNA ends. The interaction between IncRNA and proteins was analyzed by RNA-Protein pull down assay, RNA immunoprecipitation, and mass spectrometry analysis. Results: ALT1 was expressed in human umbilical vein endothelial cells (HUVECs). The expression of ALT1 was significantly downregulated in contact-inhibited HUVECs and in hypoxia-induced, growth-arrested HUVECs. Knocking down of ALT1 inhibited the proliferation of HUVECs by GO/G1 cell cycle arrest. We observed that angiotensin converting enzyme II (ACE2) was a direct target gene of ALT1. Knocking-down of ALT1 or its target gene ACE2 could efficiently decrease the expression of cyclin D1 via the enhanced ubiquitination and degradation, in which HIF- $1 \alpha$ and protein von Hippel-Lindau (pVHL) might be involved. Conclusion: The results suggested the human long non-coding RNA ALT1 is a novel regulator for cell cycle of HUVECs via ACE2 and cyclin D1 pathway.
\end{abstract}

W. Li, R. Wang and J. Ma contributed equally to this work.

Shen-ming Wang,

Wen Li, or Chunxiang Zhang
The first affiliated hospital of Sun Yat-sen University,

58 Zhongshan Second Road, Guangzhou, (P.R. China)

E-Mail shenmingwang@hotmail.com,wenli28@163.com

\section{KARGER}




\section{Cellular Physiology Cell Physiol Biochem 2017;43:1152-1167

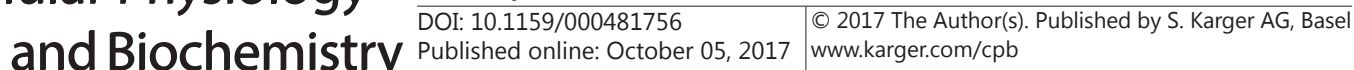 \\ Li et al.: ALT1 in Cell Cycle of Vascular Endothelial Cells}

\section{Introduction}

Long noncoding RNAs (lncRNAs) are defined as noncoding RNAs longer than 200 nucleotides and lack protein-encoding capacity, which are subgrouped into antisense, intronic, intergenic, sense overlapping and bidirectional transcripts [1,2]. In contrast to other non-coding RNAs such as microRNAs, studies of lncRNAs in biomedicine are still in their infancy due to much more complex and diverse gene regulation mechanisms [1, 2]. However, increasing evidence has shown clearly that lncRNAs have strong biological functions and may be involved in all biological and disease processes [1-4].

A human long noncoding RNA ALT1 (GenBankaccession no: AF380424) is an alternatively spliced transcript of deleted in lymphocytic leukemia 2 (DLEU2), which maps to a critical region at 13q14.3 that is recurrently deleted in malignancy [5]. Although another transcript from DLEU2 was found to be the critical host gene of miR-15a and miR-16-1 and could play critical role in cell cycle progression and cell proliferation in tumor cells via miR-15a and miR-16-1 [6, 7], the biological roles of ALT1 has never been studied.

Angiotensin converting enzyme 2 (ACE2) converts angiotensin II (Ang II) into peptides including angiotensin-1-7 (Ang1-7) and angiotensin-1-9 that counteract the effects of Ang II through Mas receptor (MasR) and angiotensin type II receptor (AT2R) respectively $[8,9]$. ACE2 activity and expression level were reported to be severely down regulated or absent in proliferating alveolar epithelial cell lines A549 and MLE-12, while its activity and expression level went much higher in quiescent A549 and MLE-12 cells [10]. Loss of ACE2 in mice enhanced the expression of genes that were induced by hypoxia and elevated mice serum Ang II, causing endothelial dysfunction, vasoconstriction and cardiac hypoperfusion [11, 12]. Ang II itself was reported to be a key mediator in the down regulation of ACE2 expression, while HIF-1 $\alpha$ inhibited ACE2 expression indirectly, both of which were depended on HIF-1 $\alpha$ accumulation during hypoxia exposure [13]. Besides, Ang1-7 treatment caused human aortic endothelial cells G0/G1 phase arrest and apoptosis [14]. These results indicate a pivotal role of ACE2 in cell cycle regulation.

In the current study, the existence and sequence of human ALT1 were identified by 3' rapid amplification of cDNA ends in human umbilical vein endothelial cells (HUVECs). Interestingly, in both contact inhibited and hypoxia-induced growth-arrested HUVEC, the expression of $A L T 1$ was significantly decreased. Knockdown of $A L T 1$ could efficiently inhibit the proliferation of HUVECs by G0/G1 cell cycle arrest via its target gene ACE2 and cyclin D1 pathway, in which HIF-1 $\alpha$ and protein von Hippel-Lindau (pVHL) might also be involved.

\section{Materials and Methods}

\section{Cell culture}

Human specimens and animal tissues acquisition and using were approved by the Institutional Review Board of the First Affiliated Hospital of Sun Yat-sen University. Human umbilical cords were obtained with consent of the donors. HUVECs were identified with CD31 antibody (Fig. 1). Primary HUVECs were ultured

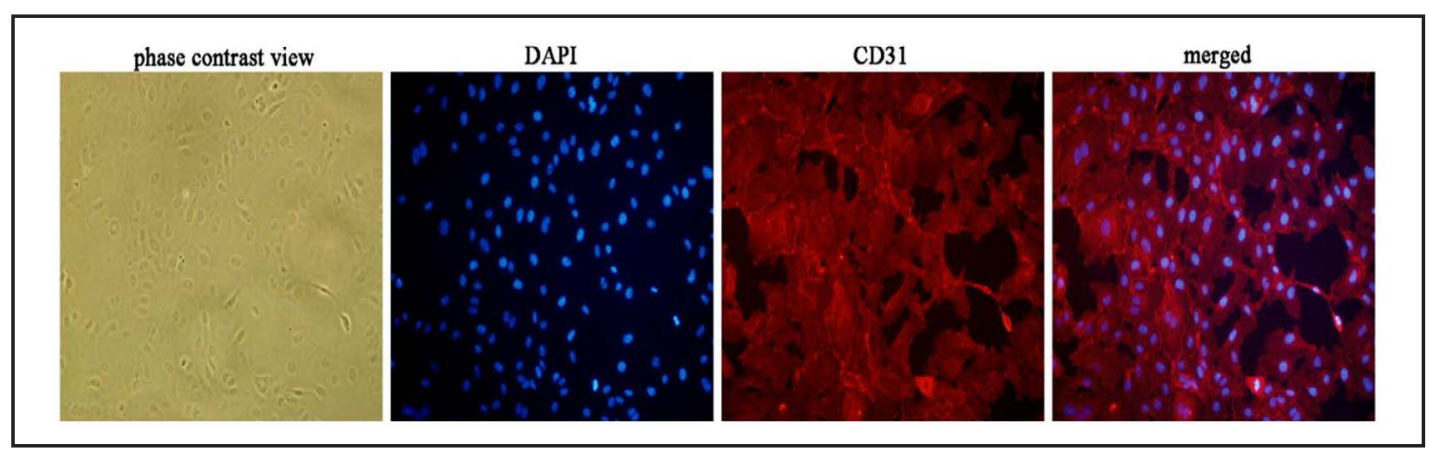

Fig. 1. Primary HUVECs were characterized with antibodies to CD31. 


\section{Cellular Physiology Cell Physiol Biochem 2017;43:1152-1167 \\ \begin{tabular}{ll|l} 
and Biochemistry $\begin{array}{l}\text { DOI: 10.1159/000481756 } \\
\text { Published online: October 05, } 2017\end{array}$ & $\begin{array}{l}\text { @ 2017 The Author(s). Published by S. Karger AG, Basel } \\
\text { www.karger.com/cpb }\end{array}$ \\
\hline
\end{tabular}}

Li et al.: ALT1 in Cell Cycle of Vascular Endothelial Cells

with $\mathrm{EGM}^{\mathrm{TM}}-2$ SingleQuots ${ }^{\circledR} \quad$ (CC-4176) medium (Lonza) supplemented with 2-5\% FBS (Gibco) and cytokines kit that sustained the cell growth and endothelial phenotype. All the cells were incubated at $37^{\circ} \mathrm{C}$ in an incubator humidified with $5 \% \mathrm{CO}_{2}$. Hypoxia exposure cells were cultured in $0.2 \% \mathrm{O}_{2}$ in a hypoxia incubator (Galaxy 170 R, New Brunswick). Cells of passages 3 to 8 were used for the experiments in the current study.

3' rapid-amplification of cDNA ends (3'-RACE)

3'RACE assay was performed with SMARTer® RACE 5'/3' Kit(TAKARA, Cat.634858), following the manufacturer's instructions. The primers used in 3'-RACE assay were designed referring to AF380424.1 provided in GeneBank (https://www.ncbi.nlm.nih.gov). Primers are listed in Table 1.

AF380424.1(ALT1) and NR_002612 in vitro transcription

AF380424.1(ALT1), NR_002612 and their corresponding antisense sequences were synthesized by bridging pieces of each sequence together through numerous polymerase chain reactions (PCR). AF380424.1, NR_002612 and their antisense were then cloned into pcDNA 3.1 for in vitro transcription assays, after the accomplishment of the synthesis of the four sequences. In vitro transcription assays were performed with MAXIscript ${ }^{2}$ T7/T3 Transcription Kit(Invitrogen), following the manufacturer's instructions.

\section{Transfection and knockdown}

For small interfering RNA oligonucleotides (siRNA) transfection experiments, cells were transfected with Lipofectamine ${ }^{\mathrm{TM}}$ RNAiMAX Reagent (Invitrogen) according to the manufacturer's instructions. siRNAs used in the current study were designed and synthesised (GenePharma, RiBio). siRNA1 (5'-ACC ACC AUU GCC GCC UUC CC dTdT-3'), siRNA2 (5'-GGU GAG AAC UGA CUA AAC U dTdT-3') and siRNA3 (5'-UGU CAG CAA AGA ACU GUA A dTdT-3') were directed against exon 7 and exon 6 of AF380424 (ALT1) respectively. In order to knock down AF380424 with a higher efficency, a mixture of two of the three siRNAs was applied in the following knock down experiment. siRNA ACE2 (5'-GAG GAG ACU AUG AAG UAA A dTdT-3') Scrambled siRNA (5'-UUC UCC GAA CGU GUC ACG U dTdT-3') was used as negative control siRNA (NC siRNA).

Cell viability assay

Cell viability was measured with Cell Counting Kit-8 (Dojindo, Japan) following the instructions. Given different cell types, 3000-5000 cells were seaded in each well of 96 well plates. The absorbance of each well was measured at $450 \mathrm{~nm}$ on a spectrophotometer (Thermo) after different small interfering RNA oligonucleotides (siRNAs) transfection, with the absorbance at $650 \mathrm{~nm}$ being subtracted to eliminate the background.

Cell cycle and apoptosis analysis

Cells were left untreated as control and transfected with indicated siRNAs. 12-24 hrs after transfection, cells were further incubated for $24 \mathrm{~h}$ before harvested. Cells were harvested and fixed overnight in $70 \%$ ethanol $(\mathrm{V} / \mathrm{V})$ and then centrifuged at $300 \times \mathrm{g}$ for 3 minutes, resuspended in 300-500 $\mu$ l PBS containing $0.3 \% \mathrm{NP}-40(\mathrm{~V} / \mathrm{V}), 20 \mu \mathrm{g} / \mathrm{ml}$ propidium iodide (Sigma) and $100 \mu \mathrm{g} / \mathrm{ml}$ RNase A (Sigma) and incubated $30 \mathrm{~min}$ at room temperature before analysis. Cell apopotosis was analyzed using Annexin V-FITC/PI kit (BD Biosciences), following the manufacturer's instructions. 20, 000 cells of each sample were counted and analyzed using FACSCalibur flow cytometer (Becton Dickinson). Both cellular DNA content and cell apoptosis ratio were analyzed using CellQuest software (BD Biosciences).

IncRNAs expression analysis and copies estimation in each cell

The IncRNAs AF380424.1(ALT1) and NR_002612 expression analysis were performed with Hs00863924_m1 and Hs03454364_m1 DLEU2 TaqMan ${ }^{\circledR}$ Gene Expression Assays (Thermo Fisher) 
respectively, GAPDH was detected with Hs00863924_m1 following the instructions. The expression level of other coding genes were performed following the protocols of subgreen real-time fluorescence quantitative PCR (qRT-PCR) as previously described [15]. Primers for subgreen qRT-PCR were listed in Table 2. The copies of ALT1 in each cell was estimated according to the linear correlation between TaqMan Gene Expression Ct values and limit dilution ALT1 expressing pcDNA 3.1 plasmids copies which was calculated with the following formulas: (1) copy number=concentration (ng/ $\mu \mathrm{L}) \times$ avogadro's constant $\left(6.02 \times 10^{23}\right) \times 10^{-9} /$ $(660 \mathrm{D} / \mathrm{nt} \times$ base number of the ALT1 expressing pcDNA 3.1 plasmid); (2) copy numbers $/ \mu \mathrm{L}=$ (mass $/$ relative molecular weight) $\times 6.02 \times 10^{23}$.

RNA-protein interaction pull down and mass spectrometry analysis

In order to get sufficient IncRNA for RNA-protein interaction pull down assay, lncRNAs DLEU2-004 (AF380424.1, ALT1), DLEU2-004 antisense, DLEU2-010(NR_002612) and DLEU2-010 antisense were all transcribed in vitro. Sequences of AF380424, NR 002612 and their antisense sequences were synthesized by a series of PCR reactions and cloned into pcDNA 3.1 plasmid vectors, so as to be templates for transcription reactions In vitro. Uracil in the IncRNAs sequences were labled by biotin during transcription reactions, which were performed with MEGAshortscript ${ }^{\mathrm{TM}}$ T7 Transcription Kit (Invitrogen ${ }^{\mathrm{TM}}$ ) following the manufacturer's instructions. Pierce ${ }^{\mathrm{TM}}$ Magnetic RNA-Protein Pull-Down Kit (Thermo Scientific ${ }^{\mathrm{TM}}$ ) was applied for RNAprotein interaction pull down assay. HUVECs were lyased with Pierce IP lysis buffer (Thermo Fisher) for protein extraction. Cell lysate was then mixed with DLEU2-004, DLEU2-004AS, DLEU2-010 and DLEU2010AS respectively. Magnetic beads labeled by streptavidin was added into the mixture and incubated for another one hour at room temperature. After incubation, the whole mixture was placed on a magnetic rack for interacting protein-lncRNA-beads complex purification, and the complex harvested in the last step was boiled with protein loading buffer at $95^{\circ} \mathrm{C}$ for 10 minutes and analyzed through SDS-PAGE, and then stained with coomassie brilliant blue.

Mass spectrometry analysis was carried out on an Ettan MALDI-TOF mass spectrometer (GE Healthcare) following protocols established and reported elsewhere previously [16]. Matching peptides from potential unknown lncRNA interacting proteins were searched against SwissPort2016 2016 (550960 sequences; 196692942 residues).

\section{RNA immunoprecipitation}

Dynabeads ${ }^{\circledR}$ Protein A for Immunoprecipitation (Novex ${ }^{\mathrm{TM}}$ ) was applied in RNA immunoprecipitation assay to analyze the interaction of IncRNAs with target proteins. The RNA immunoprecipitation assay was carried out with Magna RIP RNA-Binding protein Immunoprecipitation Kit (17-700, Millipore) following manufacturer's instructions. The protein A beads that were harvested at the final step of immunoprecipitation were separated equally into two parts: A and B. A, ALT1 from part A beads were extracted with Trizol and quantified by TaqMan probe qRT-PCR. B, proteins in part B beads were analyzed with western blotting. 


\section{Cellular Physiology Cell Physiol Biochem 2017;43:1152-1167

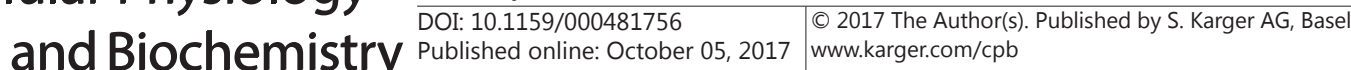

Western blotting

Cells were washed with PBS and lysed with ice-cold lysis buffer (50 mM Tris- $\mathrm{HCl}$ pH 8.0, $150 \mathrm{mM} \mathrm{NaCl,} \mathrm{1 \%} \mathrm{TritonX-100,} 5$ mM EDTA, 0.5\% SDS, $0.1 \mathrm{mM}$ PMSF and 1\% proteinase inhibitor cocktail). The lysates were then centrifuged (12000 rpm) at $4^{\circ} \mathrm{C}$ for $15 \mathrm{~min}$. The protein concentrations of each groups were then determined with a BCA Kit(Thermo Fisher). Equal amounts of cell lysates (30-50 $\mu$ g protein/ lane) were loaded into $8 \%$ or $10 \%$ SDSpolyacrylamide gels. Western Blotting was performed with Bio-Rad system. Proteins were then transferred to PVDF, and then blocked with 5\% milk in TBST. The blots were subsequently incubated overnight with specific primary Abs against ACE2 (abcam, cell signaling, proteintech) Cyclin D1(abcam), HIF-1a(proteintech), pVHL(sigma), CUL1 (proteintech), TRIM13 (cell signaling) and $\beta$-TUBULIN (proteintech), etc., followed by secondary antibody incubation. The images and bands' gray-scale values were taken and analyzed by Image Quant Las 4000 mini (GE Healthcare).

\section{Statistics}

Data are presented preferably as mean \pm SD. The Student $t$ test and one-way ANOVA test were applied to distinguish the statistically significant differences among groups. The statistically significant level was set at 0.05. All data were processed using GraphPad Prism 5.0 (GraphPad, San Diego, CA), and the statistical analysis was performed with SPSS software, version 16.0 (SPSS Inc, Chicago, IL).

\section{Results}

ALT1(AF380424.1), but not NR_002612(DLEU2-010) is expressed in HUVECS

ALT1 is a known lncRNA transcribed from DLEU2. However, the entire length and sequence of human ALT1 have not been identified. By using the 3' rapid amplification of cDNA ends (RACE) assay, we found that the entire length of ALT1 was 43 nt longer than AF380424.1 in HUVECs. The sequence of the 43 nt is TTT GTG GCC TGC ATG CTT GTA AAT TAA AAT GCA TTG AGT TGT C. The copy number of ALT1 is approximately 80-100 copies per cell. In contrast, another transcript of DLEU2 NR_002612 (DLEU2-010) could be barely detected in HUVECs (Fig. 2).

ALT1 expression is decreased in HUVECs with contact inhibition or with hypoxia-induced growth arrest

To provide a potential link of ALT1 and biological function in HUVECs, we determined the expression levels of ALT1 in HUVECs with contact inhibition, in HUVECs with hypoxiainduced growth arrest, in their control HUVECs. Interestingly, as shown in Fig. 3A, hypoxia exposure or contact inhibition could decrease ALT1 significantly in HUVECs .

Knocking down of ALT1 declines HUVECs proliferation

ALT1 level in HUVECs was knocked down with 50 nM siRNA1, siRNA2, siRNA3 respectively. Cell viability was analyzed with cck-8 kit. siRNA1 and siRNA3 could decrease ALT1 levels in HUVECs (Fig. 3B). siRNA1 and siRNA3 declined HUVEC viability significantly (Fig. 3C). siRNA2 was not applied in the following studies, as it's lower efficiency in decreasing ALT1 level. 


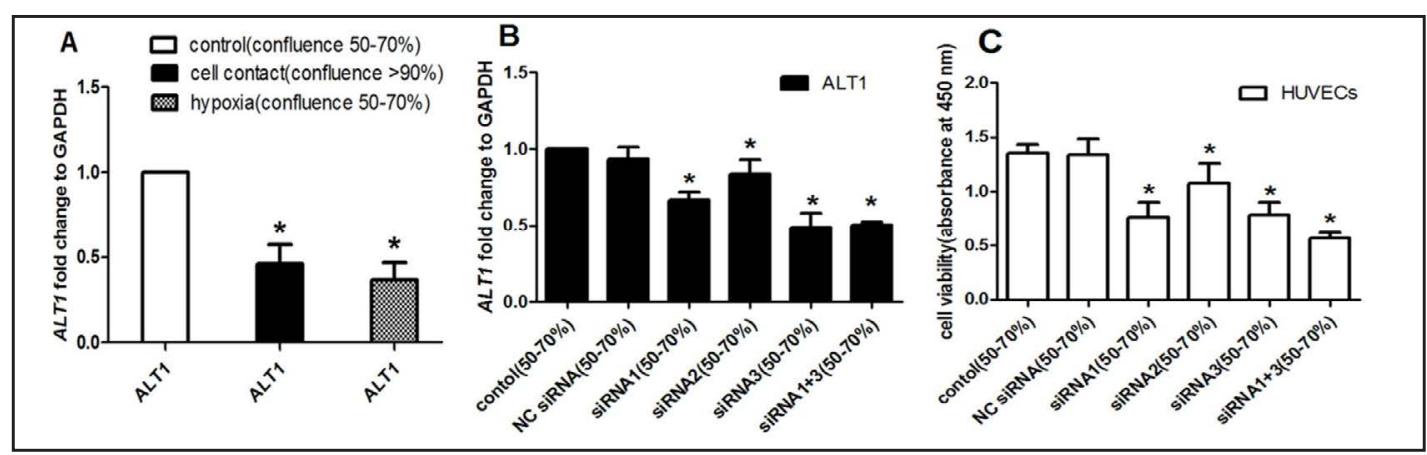

Fig. 3. Knocking down of ALT1 declines HUVECs proliferation. A. The effects of siRNA1, siRNA3 and siRNA1+3 on the expression of ALT1 in HUVECs. B. The effect of ALT1 knocking down on HUVECs proliferation. C. ALT1 knockdown declines HUVEC viability. * $\mathrm{P}<0.05$, compared with control.

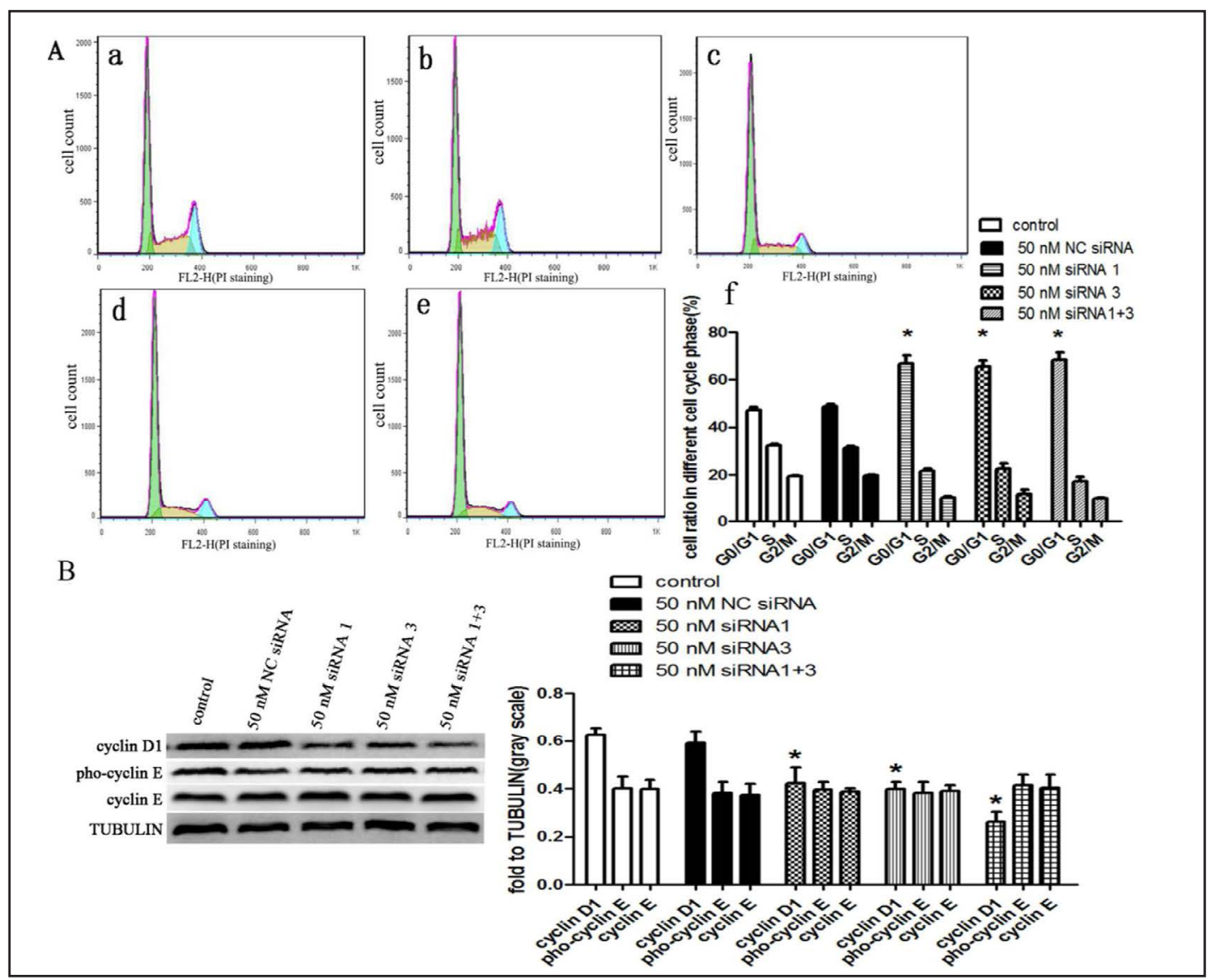

Fig. 4. Knocking down of ALT1 induces cell cycle arrest of HUVECs in G0/G1 and decreases the cyclin D1 level. A. Y-axis is cell count; X-axis is Propidium Iodide (PI) staining, FL2 channel. a. control, b. NC siRNA, c. siRNA1, d. siRNA3, e. siRNA1+3, f. cell ratio in different cell cycle phase. B. cyclin D1, cyclin E and Pho-cyclin E levels in different groups. Compared with control or NC siRNA, ${ }^{*} \mathrm{P}<0.05$.

Knocking down of ALT1 induces cell cycle arrest of HUVECs in GO/G1

In order to find why the decreasing of ALT1 level decreased HUVECs viability, we performed cell cycle analysis. siRNA1, siRNA3 and siRNA1+3 could significantly induce 


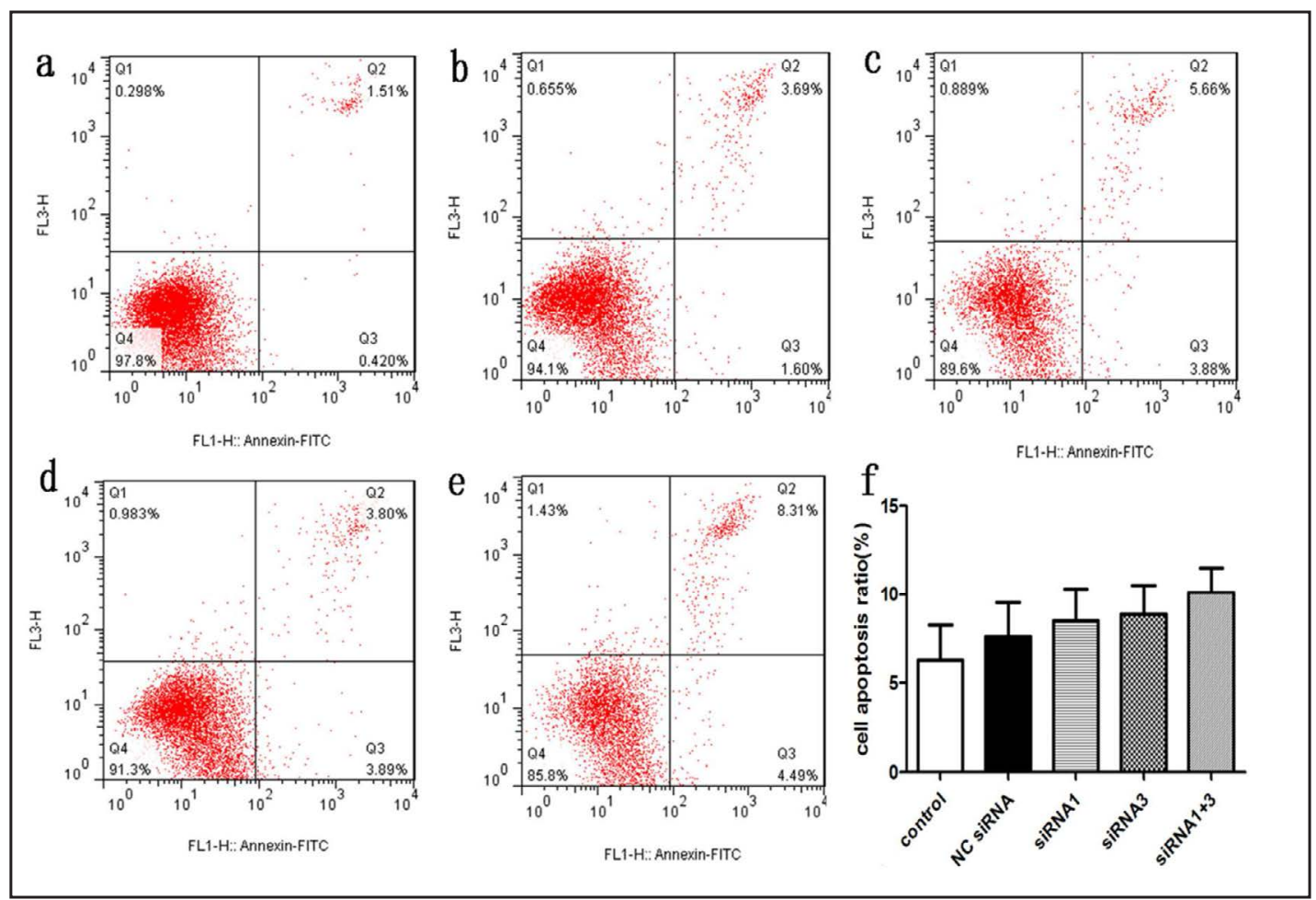

Fig. 5. Cell apoptosis was analyzed with flow cytometry, with Anexin V and PI staining. a control, b NC siRNA, c siRNA1, d siRNA3, e siRNA1+3, f cell apoptosis ratio comparison between NC siRNA and siRNA1, siRNA3 and siRNA1+3 respectively.

cell cycle arrest in G0/G1, compared with siRNA control (Fig. 4A). We further explored whether decreasing of ALT1 level interfered cyclin D1 or cyclin E protein level. Compared with NC siRNA, cyclin D1 level was decreased in HUVECs by siRNA1, siRNA3 and siRNA1+3 transfection, but did not interfered cyclin E and phosphorylation cyclin E levels (Fig. 4B). Cell apoptosis of different groups was analyzed with flow cytometry 36 hours later after siRNA transfection. But we found no significant difference among different groups, which suggested that decreasing ALT1 level did not activate cell apoptosis directly (Fig. 5). Besides, we also detected the effects of ALT1 knockdown on the expression of proteins involved in autophagy and apoptosis, at 36 hours after siRNA transfection. We found that the levels of P62, LC3 I / II, total caspase 3 did not change with the knockdown of ALT1. Since ALT1 was characterized to be the antisense of RFP2 which encodes TRIM 13 [6], we also detected TRIM13 level of each group. The TRIM13 levels were not interfered by the decreasing of ALT1 level (Fig. 6).

Decreasing of ALT1 does notchange the miR-15a, miR-15b and miR-16-1 level, but increases the expression levels of KPNA3, C13ORF1

MiR-15a, miR-15b, miR-16-1, KPNA3, C13ORF1 and RFP2 are ALT1 adjacent genes. To determine the effects of $A L T 1$ on the expression of them, the total RNAs were harvested at 36 hours after siRNA1+3 transfection. KPNA3, C13ORF1 mRNA expression level was significantly upregulated in siRNA1+3 group $(P<0.05)$, while $R F P 2$ mRNA expression level was higher in siRNA1+3 group without significance $(P>0.05)$. The levels of miR-15a, miR-15b and miR16-1 were not changed statistically significant by siRNA1+3 transfection $(P>0.05)$ (Fig. 7).

ALT1 interacts with ACE2 and CUL1 in HUVECS

RNA-Protein pull down assays were performed to identify the proteins interacted with ALT1. Compared with ALT1 antisense, NR_002612 sense and NR_002612 antisense, ALT1 KARGER 


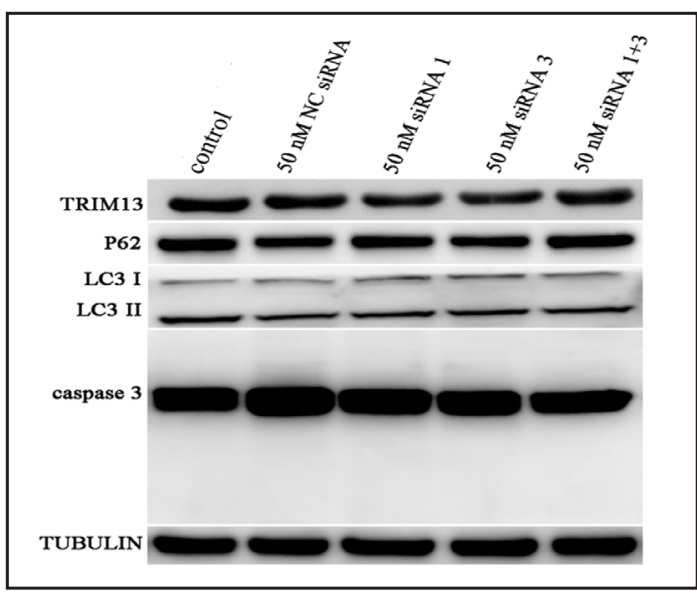

Fig. 6. TRIM13, p62, LC3I/II, caspase3 levels in control, NC siRNA, siRNA1, siRNA3, siRNA1+3 groups.

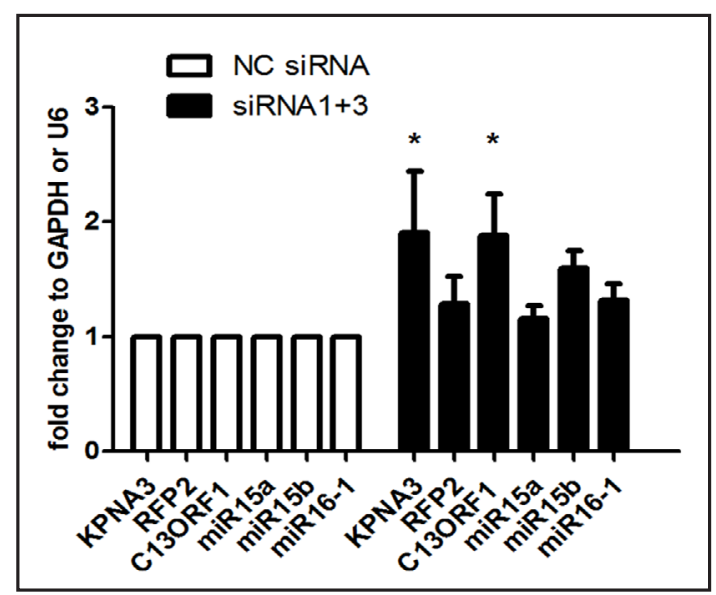

Fig. 7. The influences of ALT1 knockdown on ALT1 adjacent genes expression. ${ }^{*} \mathrm{P}<0.05$, compared with NC siRNA group.

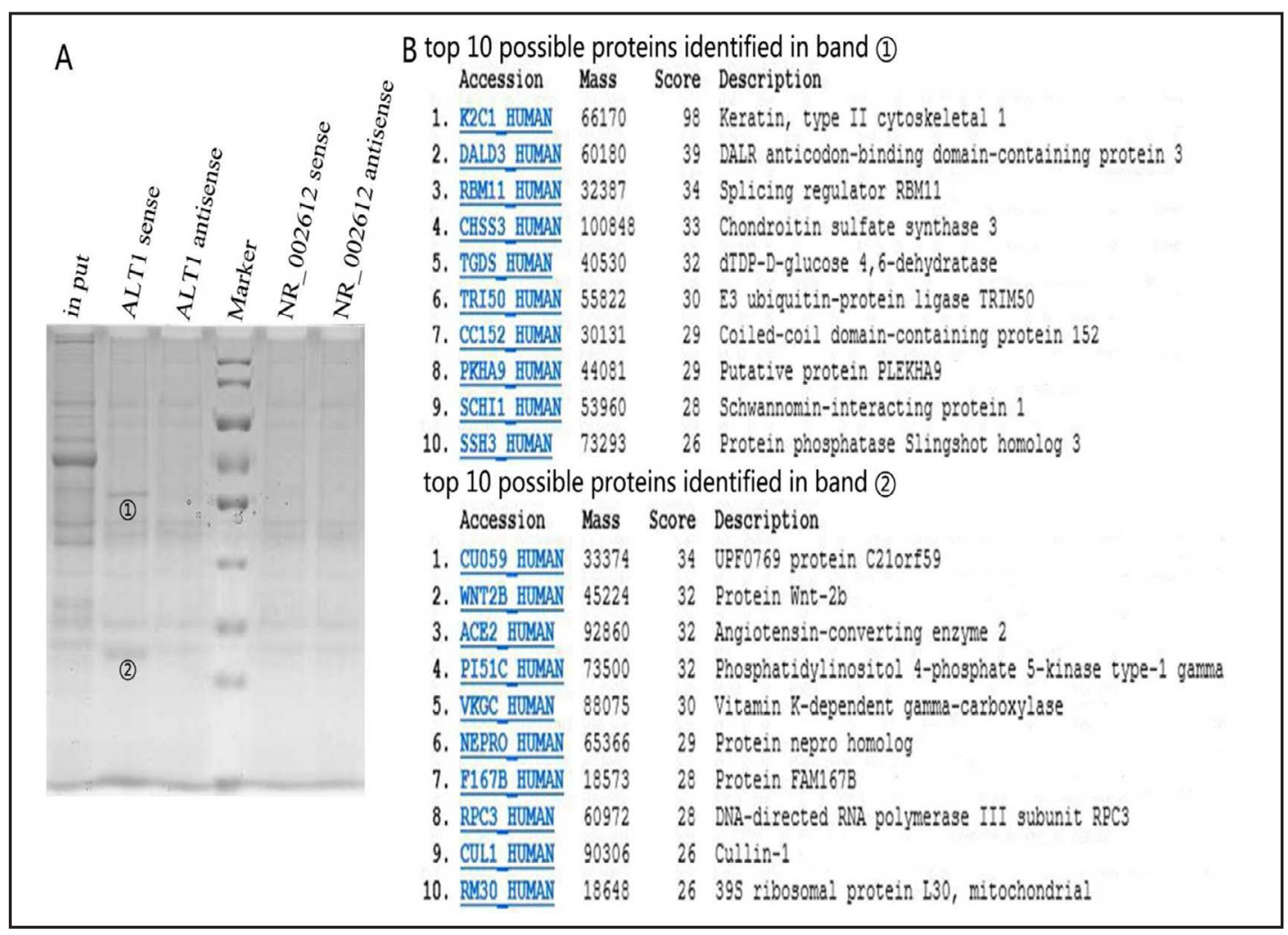

Fig. 8. ALT1 interacts with ACE2 and CUL1 in HUVECs. ALT1, NR_002612 sense and their antisense strands were transcribed in vitro and verified by sequencing. Biotinylated lncRNAs were incubated with cell lysate. Proteins that interacted with lncRNA were pulled down by streptavidin labeled magnetic beads. A. proteins pulled down with IncRNA strands were analyzed by SDS PAGE and stained with coomassie brilliant blue. Differential bands that were pulled down by ALT1 strand were marked with (1) and (2) respectively. B. Proteins included in the two bands were then identified by mass spectrometer. Proteins with top 10 possibilities were listed.

was found to be pulled down with two different protein bands (1) and (2) (Fig. 8A). Proteins that included in the two bands were then identified by mass spectrometer, and the top 10 suspected proteins were listed (Fig. 8B). 
Fig. 9. RNA immunoprecipitation of ALT1 with ACE2 or CUL1. A. ALT1 retrieved from antibody-labeled protein A beads were extracted with Trizol and quantified by TaqMan probe qRT-PCR. B. Proteins arrested with antibody-labeled protein A beads were analyzed with western blotting.

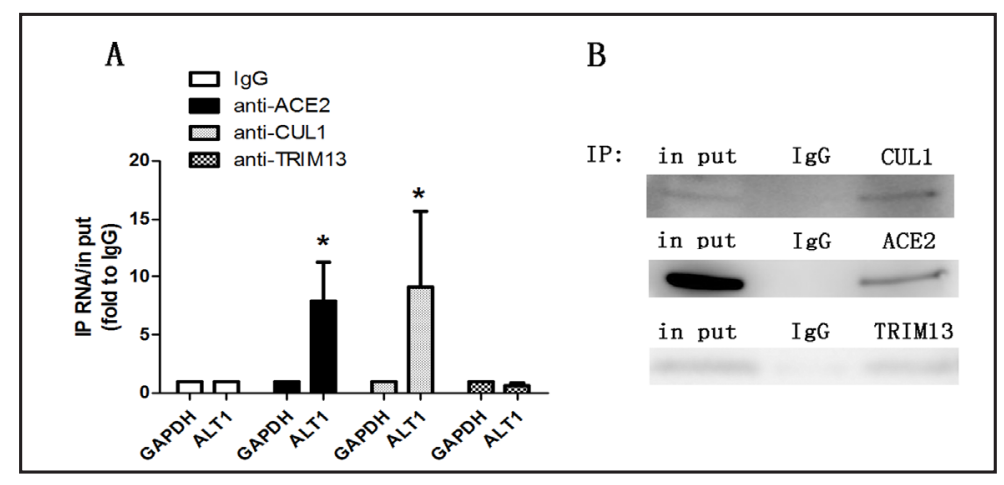

Fig. 10. Analysis of the interaction between ACE2 and CUL1 by co-immunoprecipitation. ACE2 was precipitated with ACE2 antibody in CO-IP assay, and ACE2 antibody was incubated first followed by CUL1 antibody incubation in WB analysis.

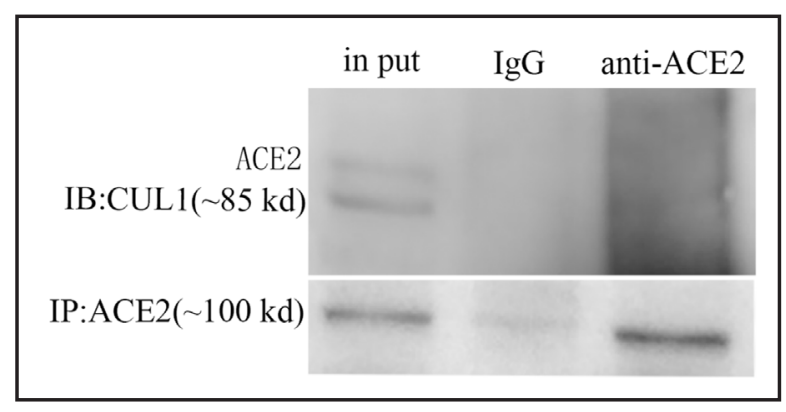

As ACE2 and CUL1 were reported to be involved in cell cycle arrest $[17,18]$, we further verified the interaction of ALT1 with ACE2 or CUL1 respectively through RNA immunoprecipitation. ALT1 could be retrieved about 2-13 folds more with ACE2 antibody and 2-15 folds more with CUL1 antibody, than with isotype control antibody IgG (Fig. 9A and 9B). Besides, ALT1 could not be retrieved with antibody to TRIM 13 (Fig. 9). We also performed co-immunoprecipitation to verify whether ACE2 could form complexes with CUL1. However, the direct interaction between ACE2 and CUL1 was not found in the current study (Fig. 10).

Knockdown of ALT1 does not alter CUL1 level, but decreases ACE2 level in HUVECS

Knockdown of ALT1 inhibited cell proliferation, leaving cell confluence at 50-70\% in siRNA1, siRNA3 and siRNA1+3 groups. Cell confluence in both control and NC siRNA group were $>90 \%$, because cell proliferation in these two groups were not affected. Decreasing of ALT1 with siRNA did not influence CUL1 level, but the ACE2 levels were significantly higher among siRNA transfection groups, compared with control (Fig. 11A). It is well known that ACE2 expression is cell cycle dependent and is very sensitive to the cell confluence levels [10]. To exclude the influence of cell confluence, we performed the experiment in controlled $50-70 \%$ cell confluence. It was clear that the expression of ACE2 was significantly reduced by ALT1 knockdown in HUVECs (Fig. 11B).

Hypoxia and cell contact inhibition decrease the ACE2 and cyclin D1 mRNA levels in HUVECS

We found that hypoxia and cell contact inhibition could decrease the expression of ALT1 (Fig. 3) and the ACE2 was a target gene of ALT1 (Fig. 8, 9 and 11). In this experiment, the effects of hypoxia and cell contact inhibition on the expression of ACE2, as well as the cyclin D1 were determined. Compared with NC siRNA transfection, hypoxia exposure and cell contact inhibition could decrease ACE2 and cyclin D1 mRNA levels (Fig. 12).

SiRNA-ACE2 reduced cyclin D1 level, but increased HIF-1 $\alpha$ level

Decreased $A L T 1$ level was found to result in the reduced ACE2 level. We further studied the effects of the decreasing ACE2 with siRNA. Hypoxia exposure increased HIF-1 $\alpha$ level despite 


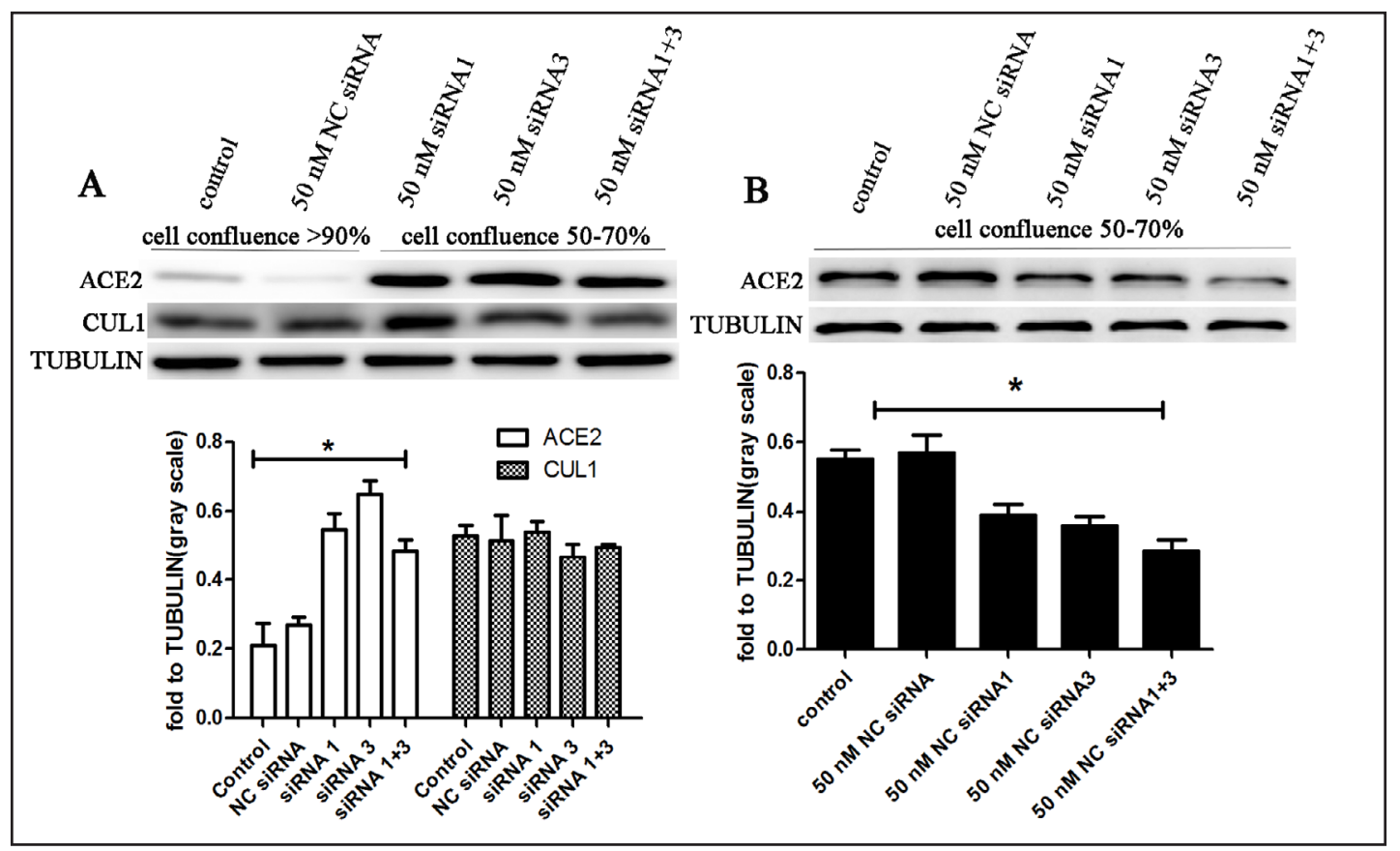

Fig. 11. The effects of ALT1 on the expression of CUL1 and ACE2 in HUVECs. A. CUL1 level was not affected by siRNA1, siRNA3 and siRNA1+3 transfection, while the ACE2 levels were significantly lower in siRNAALT1 transfection group than that in control and NC siRNA transfection group. B. Cell confluence of each group was controlled within $50-70 \%$ by seeding different cell number in different wells of 6 well plates. Compared with both control and NC siRNA, ${ }^{*} \mathrm{P}<0.05$.

the cell confluence. Decreasing ALT1 and ACE2 with siRNA respectively could significantly increase HIF$1 \alpha$ level $(P<0.05)$. In addition, the decreasing ALT1 reduced both cyclin D1 and ACE2 expression levels. $(P<0.05)$. Knocking down of ACE2 with siRNA could also decrease cyclin D1 level $(P<0.05)$ (Fig. 13). Protein von Hippel-Lindau (pVHL) level in each group was intangible during the repetition of the experiment. Therefore, the differences of pVHL levels among different groups were not statistically analyzed temporally. We then controlled cell confluence at $<70 \%$, and focus on the effects of siRNA1+3, siRNA ACE2 and hypoxia on phosphorylation retinoblastoma (phospho-RB) and pVHL levels. Knockdown of ALT1 and ACE2 significantly reduced phospho-RB levels and increased HIF- $1 \alpha$ and pVHL levels. (Fig. 14).

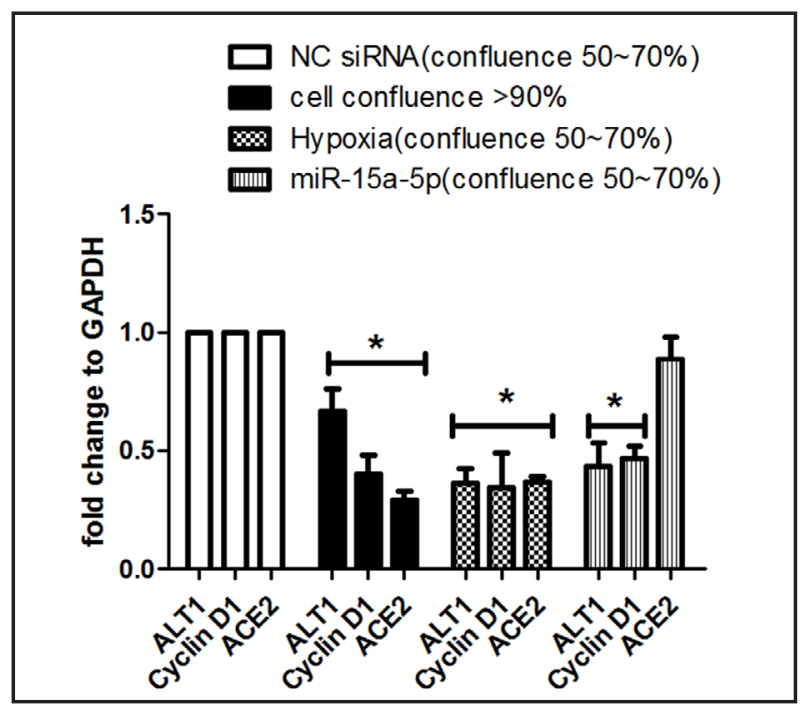

Fig. 12. The effects of hypoxia and cell contact inhibition on the expression of ACE2 and cyclin D1in HUVECs. ALT1, ACE2 and cyclin D1 mRNA fold changes in hypoxia and cell contact inhibition. Cell confluence of each group was controlled within $50-70 \%$ by seeding different cell number. Compared with NC siRNA, ${ }^{*} \mathrm{P}<0.05$. 
Fig. 13. The effects of hypoxia exposure, cell contact inhibition and siRNA-ACE2 transfection on expression levels of HIF$1 \alpha$, ACE2 and cyclin D1. HIF- $1 \alpha$ levels in both control and NC siRNA group were compared with the HIF-1 $\alpha$ levels in other groups, ${ }^{*} \mathrm{P}<0.05$. ACE2 levels in both control and NC siRNA groups were compared with the ACE2 levels in other groups, \# $\mathrm{P}<0.05$. cyclin D1 levels in both control and NC siRNA group were compared with the cyclin D1 levels in other groups, \&P<0.05.

Decreasing ALT1 with siRNA directly induces cyclin D1 ubiquitination

It was reported that cyclin D1 was ubiquitinated and subsequently degraded by pVHL in a cell density dependent manner [19]. Co-immunoprecipitation was performed with cyclin D1 antibody, and found that knock-

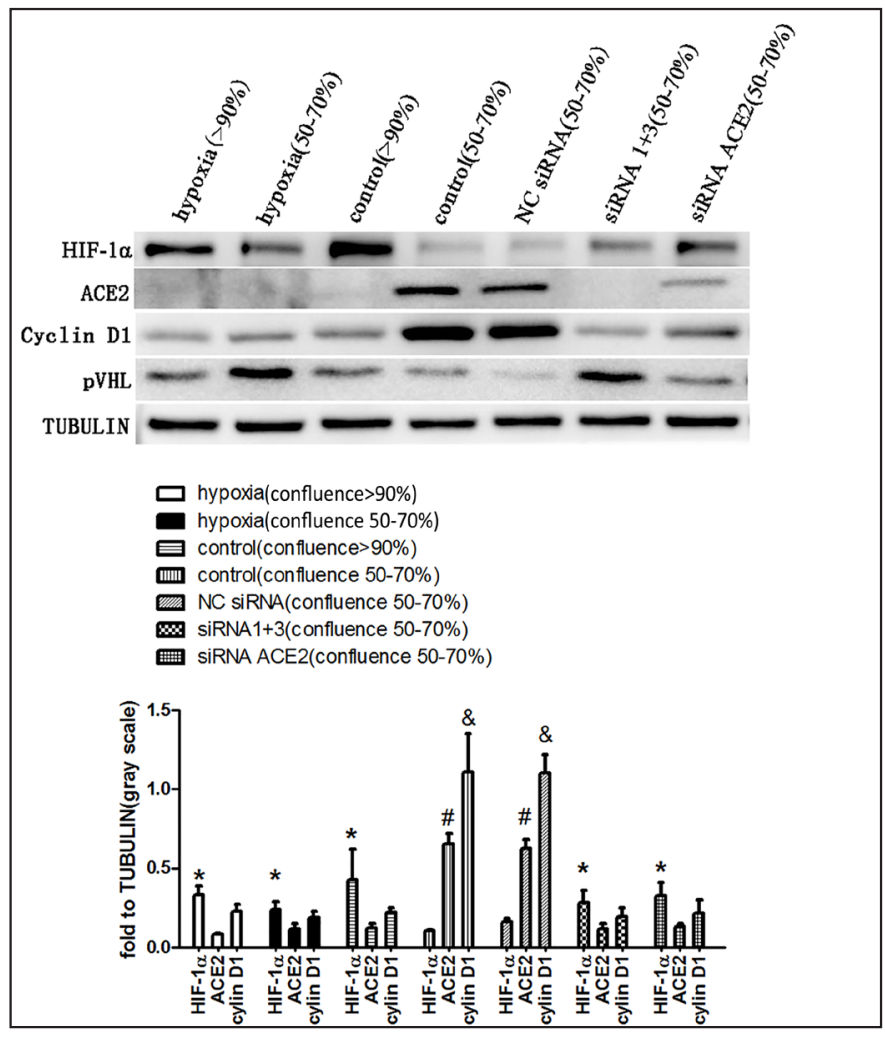
down of ALT1 or ACE2 with siRNA respectively could directly lead to cyclin D1 ubiquitination. siRNA1+3 and NC siRNA were transfected into HUVECs of different groups. In NC siRNA group, cell confluence naturally reached to $>90 \%$, which resulted in cell contact inhibition and caused cyclin D1 ubiquitination. However, siRNA1+3 transfection significantly induced cyclin D1 ubiquitination and inhibited cell proliferation, leaving cell confluence at about 50-70\% (Fig. 15).

\section{Discussion}

ALT1 is an alternative splice variant of the DLEU2 Gene [5]. Alt1 is conserved in mouse, but its sequence may be much shorter than ALT1 in human $[5,6]$. In this study, the existence and 3' end sequence of human ALT1 were identified by using the 3'-RACE. To date, several homology lncRNAs are found to be transcribed from DLEU2, including NR_002612 which is the longest variant. ALT1 was reported to be regulated by methylation and to be involved in nuclear factor- $\kappa B$ pathway regulation [20]. However, the functions of ALT1 in cell biology are still unknown.

In the current study, we found that the copy numbers of ALT1 per cell was estimated to be about 80-100 in HUVECs, through TaqMan probe assay. However, NR_002612 copy numbers in HUVECs could merely be detected (Fig. 2). The estimated ALT1 copy numbers in HUVECs was similar to IncRNA-ATB, which is activated by TGF- $\beta$ in SMMC-7721 hepatoma cells [21].

Knockdown of ALT1 level with siRNA showed clearly that siRNA could significantly decrease ALT1 level in HUVECs, which was verified with TaqMan probe assay (Fig. 16). Decreasing of ALT1 level in HUVECs resulted in significant cell viability reduction. The underlying mechanisms remain unknown, and this was also the reason that we carried on the following experiments in HUVECs. The reduction of HUVECs cell viability was resulted from cyclin D1 degradation after knockdown of ALT1. This was further validated by G0/G1 cell cycle arrest that was detected with flow cytometry after siRNA transfection. Consistent with 
Fig. 14. The effects of hypoxia exposure, siRNA $1+3$ and siRNA-ACE2 transfection on expression levels of HIF- $1 \alpha$, phospho-RB, cyclin D1 and pVHL. HIF- $1 \alpha$ levels compared with HIF-1 $\alpha$ levels in both control and NC siRNA group respectivly, ${ }^{*} \mathrm{P}<0.05$. Phospho-RB levels compared with Phospho-RB levels in both control and $\mathrm{NC}$ siRNA group respectivly, $\# \mathrm{P}<0.05$. cyclin D1 levels compared with cyclin D1 levels in both control and NC siRNA group respectivly, $\Phi \mathrm{P}<0.05$. pVHL levels compared with pVHL levels in both control and NC siRNA group respectivly, \& $\mathrm{P}<0.05$.

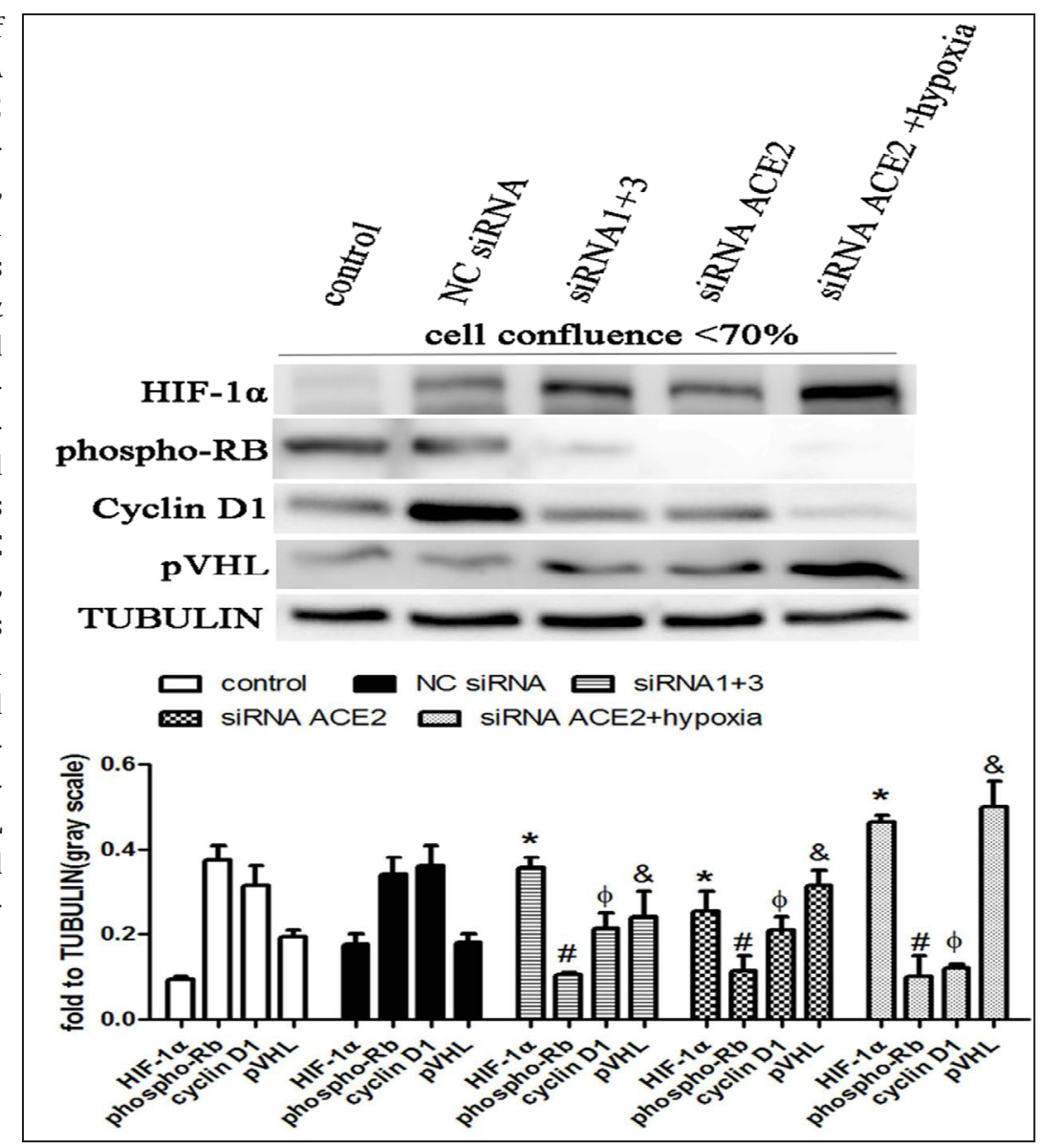

Fig. 15. Analysis of cyclin D1 ubiquitination by co-immunoprecipitation. Cyclin D1 was pulled down with cyclin D1 antibody and the ubiquitination of cyclin D1 was detected with ubiquitin antibody. MG $132(1 \mu \mathrm{M}, 12$ h) was applied to prevent ubiquitinated cyclin D1 from degradation by protease.

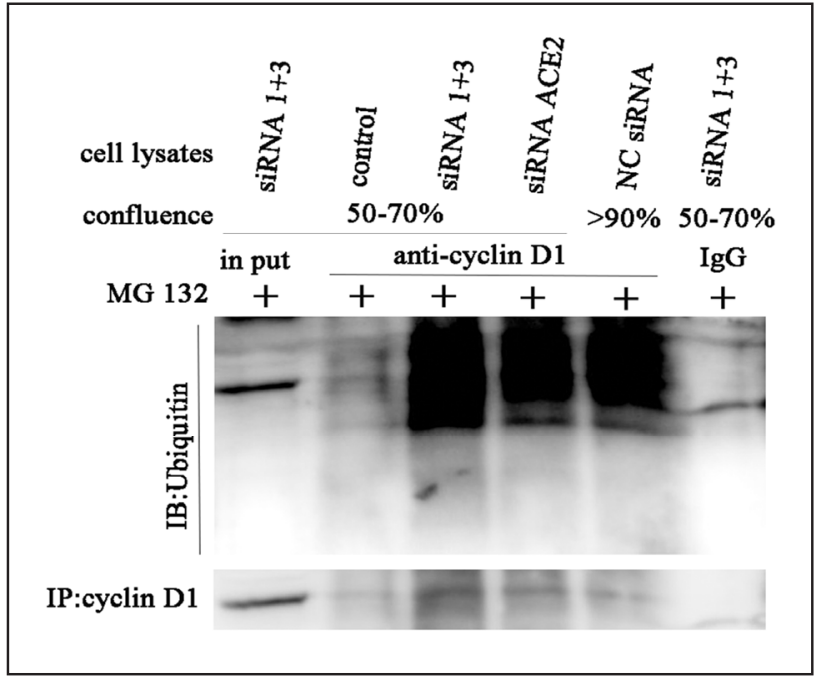

this, cyclin D1 level was significantly reduced after knockdown of ALT1, while both total cyclin $\mathrm{E}$ and phosphorylation cyclin E levels remained unchanged in different siRNA transfection groups. Besides, it was reported that TRIM13 regulates caspase- 8 ubiquitination during ER stress and induced cell death [22]. But in the current study, TRIM13, total caspase-3 levels and cell apoptosis rate were not changed significantly by knockdown of ALT1 (Fig. 5 and 6). Therefore, knockdown of ALT1 might not directly activate apoptosis or autophagy. All these mentioned above suggested that ALT1 was directly involved in cyclin D1 degradation.

\section{KARGER}




\section{Cellular Physiology Cell Physiol Biochem 2017;43:1152-1167

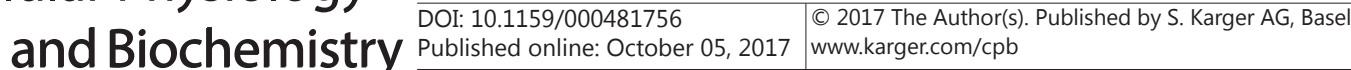 \\ Li et al.: ALT1 in Cell Cycle of Vascular Endothelial Cells}

RNA pull-down assays were then performed to explore RNA-protein interaction. ACE2 and CUL1 were found to be directly interacted with ALT1, which was further verified by RNA immunoprecipitation with ACE2 and CUL1 antibodies. In prostate cancer cells, expression of cyclin D1 and cyclin E were decreased after CUL1 knockdown [18]. CUL1 level was not influenced by knockdown of ALT1 in the current study, the role of interaction between CUL1 and ALT1 remains obscure. ACE2 is a carboxypeptidase, which was first identified in year 2000 [23, 24]. Ang I and Ang II can be metabolized by ACE2 to Ang-(1-9) and Ang-(1-7) respectively [24, 25]. ACE2/Ang-(1-7)/MAS receptor axis was reported to counteract the ACE/ Ang I /AT1R axis playing vasodilatory, anti-inflammatory and anti-proliferation roles [8, 26, 27]. ACE2 activity and expression level were reported to be severely down regulated or absent in proliferating alveolar epithelial cell lines A549 and MLE-12, while its activity and expression

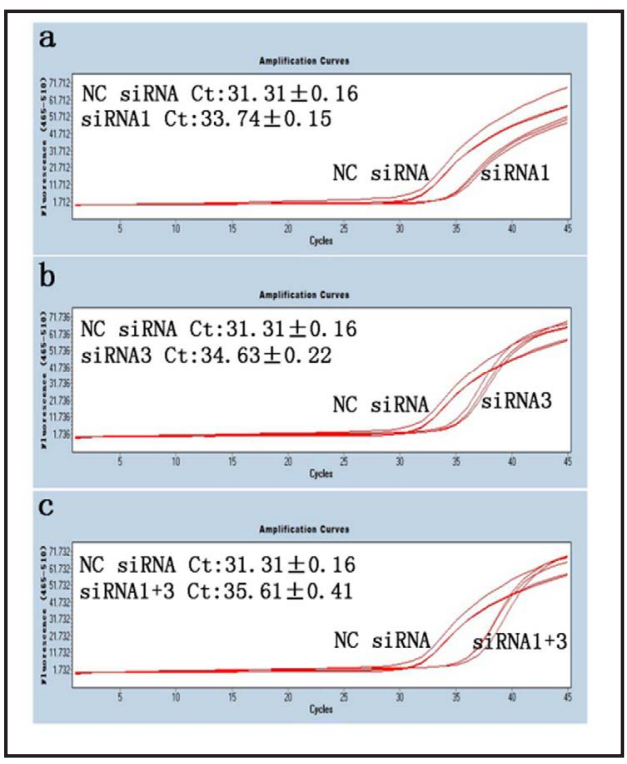

Fig. 16. Knockdown of ALT1 in HUVECs with siRNA. a. NC siRNA and siRNA 1, b. NC siRNA and siRNA3, c. NC siRNA and siRNA1+3. level went much higher in quiescent A549 and MLE-12 cells [10]. However, in the current study, both ACE2 mRNA and protein levels were significantly down regulated by both cell contact inhibition and ALT1 knockdown in HUVECs.

Indeed, ACE2 could barely be detected when cell confluence was above $90 \%$, and decreasing of ALT1 level did not elevate ACE2 level but rather reduced ACE2 level and caused cell cycle arrest. This discrepancy might be explained by different ACE2 isoforms translated from different transcripts in different source of cells [28, 29]. In fact, not only ACE2 level was reduced by ALT1 knock down in the current study, but also the HIF-1 $\alpha$ level was elevated. In accordance with our results, the expression of genes induced by hypoxia was increased in ACE2 knockout mice, causing endothelial dysfunction [12]. Furthermore, ACE2 was reported to be down regulated indirectly by HIF- $1 \alpha$ accumulation in human pulmonary artery smooth muscle cells [13]. Taken together, it is tempting to conclude that knockdown of ALT1 reduced ACE2 by either direct effect (direct target) and indirect effect via the increased HIF-1 $\alpha$. Although the underlying mechanism of increasing HIF-1 $\alpha$ level by ALT1 knockdown remains unknown, ALT1 level was found to be down regulated by hypoxia, and cell contact inhibition (in vitro) in HUVECs. Hypoxia might be caused by imbalance between supply and consumption of oxygen [30]. It was proposed that hypoxia caused by imbalance between oxygen consumption and supply in arterial wall plays key roles in atherosclerosis development [30, 31]. ALT1 level reduction caused by hypoxia might be one of the mechanisms underlying endothelial dysfunction caused by hypoxia during the early stage of atherosclerosis development. Based on this, hypoxia induced ALT1 reduction in the current study has shed light on the roles of IncRNAs that are regulated by hypoxia in early stage of atherosclerosis. Cyclin D1 was reported to be substrate of pVHL by expression array analysis between $V H L$ defective and intact $V H L$ cell lines [32]. In the current study, pVHL levels were elevated in siRNA1+3, siRNA-ACE2 and especially in siRNA-ACE2+hypoxia group. The trend of pVHL expression levels was in line with that of HIF- $1 \alpha$ level. This accordance was supported by a previous study which concluded that pVHL is required for cyclin D1 degradation at a high cell density through HIF in renal carcinoma 786-0 cells [19]. Cyclin D1 was also ubiquitinated at a high cell density in the current study, and decreasing of ALT1 with siRNA1+3 directly induced cyclin D1 ubiquitination as well. A similar conclusion might be made from the current study, because HIF- $1 \alpha$ level was increased after ALT1 knockdown. Furthermore, cyclin D1 ubiquitination was also induced by knockdown of ACE2 which significantly increased HIF- 
Fig. 17. Summarized pathway of ALT1 in HUVECs cell cycle regulation. (1) whether Skp1-Cdc53/Cul1-F-box complex exists in HUVECs, and what is the substrate? (2) How does ACE2 participate in HIF-1 $\alpha$ degradation.

$1 \alpha$ level under normoxia at a low cell density. ACE2 is a carboxypeptidase. ACE2 deficiency caused upregulation of genes induced by hypoxia [12]. ACE2 knockdown caused increased HIF- $1 \alpha$ level in the current study. Taken together, there is a possibility that ACE2 might hydroxylate the conserved proline residue of HIF- $1 \alpha$. HIF $\alpha$ could be degraded in an oxygen dependent manner by pVHL when the conserved proline residue was hydroxylated $[33,34]$. pVHL loss caused HIF $\alpha$ accumulation and exerted similar effects to ACE2 knockout, including

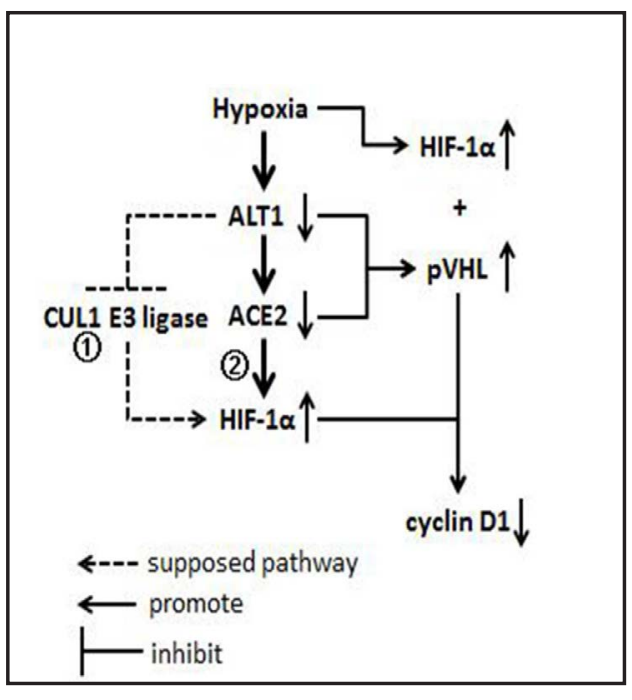
up-regulation of hypoxia-inducible genes [35, 36].

Besides, sequence and structural similarities was found between the identified complex pVHL/elongin C/elongin B/Cul2 and the yeast Skp1-Cdc53/Cul1-F-box complex [37, 38]. This might suggest that the interaction between ALT1 and CUL1 which was found in the current study is involved in the process of cyclin D1 ubiquitination and degradation by pVHL as well.

In summary, knockdown of ALT1 or its target gene ACE2 could efficiently decrease cyclin D1 level via the enhanced ubiquitination and degradation, in which HIF- $1 \alpha$ and protein von Hippel-Lindau (pVHL) was involved. The results suggested the human long non-coding RNA ALT1 is a novel regulator for cell cycle of HUVECs via ACE2 and cyclin D1 pathway (summarized in Fig. 17). However, the role of ACE2 in regulation of HIF-1 $\alpha$ level and the role of interaction between ALT1 and CUL1 remains obscure in ALT1 mediated cyclin D1 ubiquitination. Two issues need to be addressed to reveal the specific mechanisms of ALT1 in regulating cyclin D1 ubiquitination: (1)whether Skp1-Cdc53/Cul1-F-box complex exists in HUVECs, and what is the substrate? (2) How does ACE2 participate in HIF-1 $\alpha$ degradation?

\section{Acknowledgements}

The current study was supported by the National Natural Science Foundation of China to Dr. Wang (81270378; 81070258), Dr. Li (81370368) and Dr Li (81300237). This study was in part supported by the Natural Foundation of Shandong Province to Doctor Li (ZR2016HQ18).

\section{Disclosure Statement}

None.

\section{References}

1 Batista PJ, Chang HY: Long noncoding RNAs: cellular address codes in development and disease. Cell 2013;152:1298-1307.

-2 Sandberg K, Samson WK, Ji H: Decoding noncoding RNA: da Vinci redux? Circ Res 2013;113:240-241.

- 3 Leung A, Trac C, Jin W, Lanting L, Akbany A, Saetrom P, Schones DE, Natarajan R: Novel long noncoding RNAs are regulated by angiotensin II in vascular smooth muscle cells. Circ Res 2013;113:266-278. 


\section{Cellular Physiology Cell Physiol Biochem 2017;43:1152-1167 \begin{tabular}{ll|l} 
and Biochemistry Published onlIne: October 05, 2017 & $\begin{array}{l}\text { (c) } 2017 \text { The Author(s). Published by S. Karger AG, Basel } \\
\text { www.karger.com/cpb }\end{array}$ \\
\hline
\end{tabular}}

Li et al.: ALT1 in Cell Cycle of Vascular Endothelial Cells

-4 Congrains A, Kamide K, Katsuya T, Yasuda O, Oguro R, Yamamoto K, Ohishi M, Rakugi H: CVD-associated non-coding RNA, ANRIL, modulates expression of atherogenic pathways in VSMC. Biochem Biophys Res Commun 2012;419:612-616.

5 Bullrich F, Fujii H, Calin G, Mabuchi H, Negrini M, Pekarsky Y, Rassenti L, Alder H, Reed JC, Keating MJ, Kipps TJ, Croce CM: Characterization of the 13q14 tumor suppressor locus in CLL: identification of ALT1, an alternative splice variant of the LEU2 gene. Cancer Res 2001;61:6640-6648.

6 Corcoran MM, Hammarsund M, Zhu C, Lerner M, Kapanadze B, Wilson B, Larsson C, Forsberg L, Ibbotson RE, Einhorn S, Oscier DG, Grander D, Sangfelt O: DLEU2 encodes an antisense RNA for the putative bicistronic RFP2/LEU5 gene in humans and mouse. Genes Chromosomes Cancer 2004;40:285-297.

7 Lerner M, Harada M, Loven J, Castro J, Davis Z, Oscier D, Henriksson M, Sangfelt O, Grander D, Corcoran MM: DLEU2, frequently deleted in malignancy, functions as a critical host gene of the cell cycle inhibitory microRNAs miR-15a and miR-16-1. Exp Cell Res 2009;315:2941-2952.

8 Simoes e Silva AC, Silveira KD, Ferreira AJ, Teixeira MM: ACE2, angiotensin-(1-7) and Mas receptor axis in inflammation and fibrosis. Br J Pharmacol 2013;169:477-492.

-9 Tsukamoto I, Inoue S, Teramura T, Takehara T, Ohtani K, Akagi M: Activating types 1 and 2 angiotensin II receptors modulate the hypertrophic differentiation of chondrocytes. FEBS Open Bio 2013;3:279-284.

10 Uhal BD, Dang M, Dang V, Llatos R, Cano E, Abdul-Hafez A, Markey J, Piasecki CC, Molina-Molina M: Cell cycle dependence of ACE-2 explains downregulation in idiopathic pulmonary fibrosis. Eur Respir J 2013;42:198-210.

11 Crackower MA, Sarao R, Oudit GY, Yagil C, Kozieradzki I, Scanga SE, Oliveira-dos-Santos AJ, da Costa J, Zhang L, Pei Y, Scholey J, Ferrario CM, Manoukian AS, Chappell MC, Backx PH, Yagil Y, Penninger JM: Angiotensinconverting enzyme 2 is an essential regulator of heart function. Nature 2002;417:822-828.

12 Liu Z, Huang XR, Chen HY, Penninger JM, Lan HY: Loss of angiotensin-converting enzyme 2 enhances TGF-beta/Smad-mediated renal fibrosis and NF-kappaB-driven renal inflammation in a mouse model of obstructive nephropathy. Lab Invest 2012;92:650-661.

13 Zhang R, Wu Y, Zhao M, Liu C, Zhou L, Shen S, Liao S, Yang K, Li Q, Wan H: Role of HIF-1alpha in the regulation ACE and ACE2 expression in hypoxic human pulmonary artery smooth muscle cells. Am J Physiol Lung Cell Mol Physiol 2009;297:L631-640.

14 Wang HJ, Chen SF, Lo WY: Identification of Cofilin-1 Induces G0/G1 Arrest and Autophagy in Angiotensin(1-7)-treated Human Aortic Endothelial Cells from iTRAQ Quantitative Proteomics. Sci Rep 2016;6:35372.

15 Wang M, Li W, Chang GQ, Ye CS, Ou JS, Li XX, Liu Y, Cheang TY, Huang XL, Wang SM: MicroRNA-21 regulates vascular smooth muscle cell function via targeting tropomyosin 1 in arteriosclerosis obliterans of lower extremities. Arterioscler Thromb Vasc Biol 2011;31:2044-2053.

16 Luo YX, Cui J, Wang L, Chen DK, Peng JS, Lan P, Huang MJ, Huang YH, Cai SR, Hu KH, Li MT, Wang JP: Identification of cancer-associated proteins by proteomics and downregulation of beta-tropomyosin expression in colorectal adenoma and cancer. Proteomics Clin Appl 2009;3:1397-1406.

17 Wang H-J, Chen S-F, Lo W-Y: Identification of Cofilin-1 Induces G0/G1 Arrest and Autophagy in Angiotensin(1-7)-treated Human Aortic Endothelial Cells from iTRAQ Quantitative Proteomics. Scientific Reports 2016;6:

18 Jiang H, He D, Xu H, Liu J, Qu L, Tong S: Cullin-1 promotes cell proliferation via cell cycle regulation and is a novel in prostate cancer. Int J Clin Exp Pathol 2015;8:1575-1583.

19 Baba M, Hirai S, Yamada-Okabe H, Hamada K, Tabuchi H, Kobayashi K, Kondo K, Yoshida M, Yamashita A, Kishida T, Nakaigawa N, Nagashima Y, Kubota Y, Yao M, Ohno S: Loss of von Hippel-Lindau protein causes cell density dependent deregulation of CyclinD1 expression through hypoxia-inducible factor. Oncogene 2003;22:2728-2738.

20 Garding A, Bhattacharya N, Claus R, Ruppel M, Tschuch C, Filarsky K, Idler I, Zucknick M, Caudron-Herger M, Oakes C, Fleig V, Keklikoglou I, Allegra D, Serra L, Thakurela S, Tiwari V, Weichenhan D, Benner A, Radlwimmer B, Zentgraf H, Wiemann S, Rippe K, Plass C, Dohner H, Lichter P, Stilgenbauer S, Mertens D: Epigenetic upregulation of IncRNAs at 13q14.3 in leukemia is linked to the In Cis downregulation of a gene cluster that targets NF-kB. PLoS Genet 2013;9:e1003373.

21 Yuan JH, Yang F, Wang F, Ma JZ, Guo YJ, Tao QF, Liu F, Pan W, Wang TT, Zhou CC, Wang SB, Wang YZ, Yang Y, Yang N, Zhou WP, Yang GS, Sun SH: A long noncoding RNA activated by TGF-beta promotes the invasionmetastasis cascade in hepatocellular carcinoma. Cancer Cell 2014;25:666-681. 


\section{Cellular Physiology Cell Physiol Biochem 2017;43:1152-1167

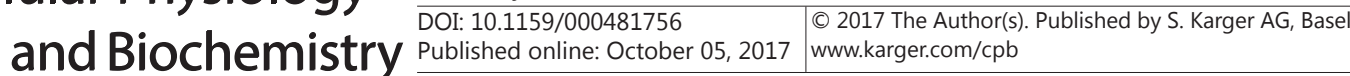

Li et al.: ALT1 in Cell Cycle of Vascular Endothelial Cells

22 Tomar D, Prajapati P, Sripada L, Singh K, Singh R, Singh AK, Singh R: TRIM13 regulates caspase-8 ubiquitination, translocation to autophagosomes and activation during ER stress induced cell death. Biochim Biophys Acta 2013;1833:3134-3144.

23 Donoghue M, Hsieh F, Baronas E, Godbout K, Gosselin M, Stagliano N, Donovan M, Woolf B, Robison K, Jeyaseelan R, Breitbart RE, Acton S: A novel angiotensin-converting enzyme-related carboxypeptidase (ACE2) converts angiotensin I to angiotensin 1-9. Circ Res 2000;87:E1-9.

-24 Tipnis SR, Hooper NM, Hyde R, Karran E, Christie G, Turner AJ: A human homolog of angiotensinconverting enzyme. Cloning and functional expression as a captopril-insensitive carboxypeptidase. J Biol Chem 2000;275:33238-33243.

-25 Vickers C, Hales P, Kaushik V, Dick L, Gavin J, Tang J, Godbout K, Parsons T, Baronas E, Hsieh F, Acton S, Patane M, Nichols A, Tummino P: Hydrolysis of biological peptides by human angiotensin-converting enzyme-related carboxypeptidase. J Biol Chem 2002;277:14838-14843.

-26 Tallant EA, Clark MA: Molecular mechanisms of inhibition of vascular growth by angiotensin-(1-7). Hypertension 2003;42:574-579.

27 Santos RA, Simoes e Silva AC, Maric C, Silva DM, Machado RP, de Buhr I, Heringer-Walther S, Pinheiro SV, Lopes MT, Bader M, Mendes EP, Lemos VS, Campagnole-Santos MJ, Schultheiss HP, Speth R, Walther T: Angiotensin-(1-7) is an endogenous ligand for the G protein-coupled receptor Mas. Proc Natl Acad Sci U S A 2003;100:8258-8263.

28 Wiener RS, Cao YX, Hinds A, Ramirez MI, Williams MC: Angiotensin converting enzyme 2 is primarily epithelial and is developmentally regulated in the mouse lung. J Cell Biochem 2007;101:1278-1291.

29 Lambert DW, Yarski M, Warner FJ, Thornhill P, Parkin ET, Smith AI, Hooper NM, Turner AJ: Tumor necrosis factor-alpha convertase (ADAM17) mediates regulated ectodomain shedding of the severe-acute respiratory syndrome-coronavirus (SARS-CoV) receptor, angiotensin-converting enzyme-2 (ACE2). J Biol Chem 2005;280:30113-30119.

30 Ferns GAA, Heikal L: Hypoxia in Atherogenesis. Angiology 2017;68:472-493.

-31 Schultz K, Fanburg BL, Beasley D: Hypoxia and hypoxia-inducible factor-1alpha promote growth factor-induced proliferation of human vascular smooth muscle cells. Am J Physiol Heart Circ Physiol 2006;290:H2528-2534.

32 Zatyka M, da Silva NF, Clifford SC, Morris MR, Wiesener MS, Eckardt KU, Houlston RS, Richards FM, Latif F, Maher ER: Identification of cyclin D1 and other novel targets for the von Hippel-Lindau tumor suppressor gene by expression array analysis and investigation of cyclin D1 genotype as a modifier in von HippelLindau disease. Cancer Res 2002;62:3803-3811.

33 Ivan M, Kondo K, Yang H, Kim W, Valiando J, Ohh M, Salic A, Asara JM, Lane WS, Kaelin WG, Jr.: HIFalpha targeted for VHL-mediated destruction by proline hydroxylation: implications for 02 sensing. Science 2001;292:464-468.

-34 Jaakkola P, Mole DR, Tian YM, Wilson MI, Gielbert J, Gaskell SJ, von Kriegsheim A, Hebestreit HF, Mukherji M, Schofield CJ, Maxwell PH, Pugh CW, Ratcliffe PJ: Targeting of HIF-alpha to the von Hippel-Lindau ubiquitylation complex by 02-regulated prolyl hydroxylation. Science 2001;292:468-472.

-35 Iliopoulos O, Levy AP, Jiang C, Kaelin WG, Jr., Goldberg MA: Negative regulation of hypoxia-inducible genes by the von Hippel-Lindau protein. Proc Natl Acad Sci U S A 1996;93:10595-10599.

-36 Lonergan KM, Iliopoulos O, Ohh M, Kamura T, Conaway RC, Conaway JW, Kaelin WG, Jr.: Regulation of hypoxia-inducible mRNAs by the von Hippel-Lindau tumor suppressor protein requires binding to complexes containing elongins B/C and Cul2. Mol Cell Biol 1998;18:732-741.

-37 Pause A, Lee S, Worrell RA, Chen DY, Burgess WH, Linehan WM, Klausner RD: The von Hippel-Lindau tumor-suppressor gene product forms a stable complex with human CUL-2, a member of the Cdc53 family of proteins. Proc Natl Acad Sci U S A 1997;94:2156-2161.

38 Ohh M, Kim WY, Moslehi JJ, Chen Y, Chau V, Read MA, Kaelin WG, Jr.: An intact NEDD8 pathway is required for Cullin-dependent ubiquitylation in mammalian cells. EMBO Rep 2002;3:177-182. 